\title{
Modern Rice Technologies and Productivity in the Philippines: Disentangling Technology from Managerial Gaps
}

\author{
Renato Villano, Boris Bravo-Ureta, Daniel Solís and \\ Euan Fleming ${ }^{1}$
}

(Original submitted September 2013, revision received June 2014, accepted July 2014.)

\begin{abstract}
Using cross-sectional farm-level data from 3,164 rice-farming households in the Philippines, we measure the impact of modern rice technologies on farm productivity while disentangling technology gaps (the distance between production frontiers) from managerial gaps (differences in technical efficiency). To do so, we combine a recently developed stochastic production frontier framework with impact evaluation techniques to control for biases stemming from observables and unobservables. First, we find an adequate control group using propensity score matching to mitigate the effect of biases from observable variables. Then, we test for biases that might arise from unobserved variables using a stochastic frontier framework corrected for self-selection. Finally, we estimate meta-frontiers to assess productivity differences between adopters and non-adopters. The analysis shows that the adoption of certified seeds has a significant and positive impact on productivity, efficiency and net income in rice farming.
\end{abstract}

\footnotetext{
${ }^{1}$ Renato Villano and Euan Fleming are Associate Professor and Professor, respectively, at the UNE Business School, University of New England, Armidale, NSW, Australia. Boris BravoUreta is a Professor in the Department of Agricultural and Resource Economics and the Department of Economics at University of Connecticut, Connecticut, USA and an Adjunct Professor in the Department of Agricultural Economics at University of Talca, Chile. Daniel Solis is an Assistant Professor at the Agribusiness Program, Division of Agricultural Sciences, CAFS, Florida A\&M University, Florida, USA. Email: rvillan2@une.edu.au for correspondence. The authors are pleased to acknowledge the Socioeconomics Division of the Philippine Rice Research Institute for the provision of the data used in this paper. In particular, the first author would like to thank Mr. Marc Mariano for his insights regarding the nature of the dataset. The authors would also like to thank participants from the 2012 Asia-Pacific Productivity Conference for comments and suggestions. Finally, we would like to acknowledge the comments and suggestions made by anonymous referees. The usual disclaimer applies.
} 
Keywords: Adoption; certified seeds; farming net income; meta-frontier; Philippines; propensity score matching; rice production; selection bias; stochastic production frontier.

JEL classifications: $C 21, Q 12, Q 16, Q 55, R 58$.

\section{Introduction}

Since the 1960s, when a technology-centred approach to agricultural research and development (R\&D) prevailed, various reforms have been implemented in the Philippines in an attempt to ensure that smallholders are fully integrated into the agricultural R\&D process so that they benefit from better access to production technologies and from improved productivity. Tenywa et al. (2011) provide a summary of these reforms culminating in the implementation of integrated centred innovation systems approaches' over the past decade. Despite these reforms, a sizable share of smallholders in developing countries has not taken up many innovations from the agricultural R\&D process; thus, full productivity impacts are yet to materialise. The lack of uptake of scientifically recommended production technologies by many rice smallholders (e.g. Kshirsagar et al., 2002; Salehin et al., 2009; Tiamiyu et al., 2009; Singha and Baruah, 2011) suggests that selfselection might be an issue among producers participating in the $R \& D$ process facilitating their access to these technologies while leaving many smallholders on the margins of the process.

A case in point is the introduction of certified seeds (CSs) in rice production in the Philippines. $^{2}$ A CS is one that has been produced under strict standards to assure its genetic purity and physical quality, and has been widely viewed as a major factor leading to higher productivity among smallholders (e.g. Mataia et al., 2011). Despite the use of modern R\&D processes, Mariano et al. (2011) reported that only $30 \%$ of sampled Philippine rice producers in 2006-07 had adopted CSs. Further, these authors doubt that early advances in total factor productivity (TFP) have been sustained in the post-Green revolution era. They also argue that it is not clear to what extent TFP growth has been due to improved CSs and how much has been caused by improved management practices. Studies have been conducted separately to measure TFP growth and factors influencing the adoption of CSs in rice production in the Philippines as will be reported below. However, no work has been conducted to disentangle the technology and managerial impacts on productivity while integrating an analysis of factors influencing the adoption of CSs.

In an effort to advance the understanding of productivity differences in rice farming in the Philippines, we examine the impact of modern rice technologies using farm-level data. In doing so, we make two main contributions. The first is to improve the understanding of the determinants of technology adoption for effective and efficient targeting efforts to increase productivity among Philippine rice farmers. The second contribution is to obtain unbiased estimates of the impact of technology adoption on productivity by addressing self-selection.

\footnotetext{
${ }^{2}$ Certified seed 'is the progeny of foundation, registered or certified seeds, handled to maintain sufficient varietal identity and purity, grown by selected farmers under prescribed conditions of culture and isolation and subjected to field and seed inspections prior to approval by the certifying agency' (IRRI, 2013, p. 1).
} 
We disentangle the effects of technology and managerial ability on the productivity of rice farmers paying special attention to two major issues. First, the decision to adopt modern technologies is likely to be affected by selectivity bias from unobservables, an issue that is typically ignored in productivity analysis (Kumbhakar et al., 2009). Second, as is frequently the case, the data available for this study were collected after the introduction of CSs in the Philippines and therefore no baseline data are available, which would be useful in addressing potential biases from both observables and unobservables. We deal with these two issues using the framework presented by Bravo-Ureta et al. (2012). This framework corrects for biases from observables using propensity score matching (PSM) and controls for biases from unobservables by implementing Greene's (2010) stochastic production frontier (SPF) corrected for sample selection. However, the framework by Bravo-Ureta et al. (2012) does not allow for a direct comparison of technical efficiency (TE) between adopters and non-adopters. We tackle this last issue by estimating meta-frontiers to generate a common technology that enables the direct comparison of TE across the two groups.

The remainder of the paper is organised as follows. In the next section, a brief history is provided of recent developments in rice production in the Philippines. Section 3 contains a review of the related literature in the area of productivity, efficiency and technology adoption in rice farming. In section 4, we outline the analytical framework. In section 5, we describe the empirical model and data sources, and present descriptive statistics and the estimation strategy. Results are presented and discussed in section 6 , and the paper ends with some concluding remarks.

\section{Recent Developments in Rice Production in the Philippines}

Rice remains an important agricultural commodity in the Philippines. It accounts for one-fifth of agricultural gross value added, is a major source of employment and income for rural people, and poor households spend about $25 \%$ of their income on rice (Balisacan and Sebastian, 2006). Given its importance in the national and political economy, rice has become one of the main focuses of $\mathrm{R} \& \mathrm{D}$, and an important topic for empirical studies in the Philippines.

The introduction of improved varieties has increased agricultural production, thus enhancing food security in many developing countries (Baker and Jewitt, 2007). Rice yields in the Philippines experienced phenomenal growth from the early 1970s to the mid-1980s as a result of the Green Revolution, comprising improved varieties, cropping intensification, expansion of irrigated areas, increased nutrient inputs and better crop management practices. Although the impressive success of the Green Revolution during the 1970s and 1980s was not sustained through the mid-1990s (Umetsu et al., 2003), recent statistics indicate that, after 1996, rice yields grew at an annual rate approaching 3\%. Mataia et al. (2011) reported that, from 1997 to 2007, the average yearly yield growth was $2.3 \%$ and $3.6 \%$ for irrigated and rainfed areas, respectively.

Technological innovations in farming have played an important role in the growth of the rice sector in the Philippines. R\&D continues to generate modern rice technologies and to make them available to farmers. The adoption of these technologies has provided opportunities for rice farming households to increase production and to improve their incomes and food security. Mataia et al. (2011) reported that one of the major contributors to gains in rice yields in the Philippines has been the adoption of high-quality seeds, especially of CSs. 
Another potentially important source of productivity growth is the improvement of managerial performance of farmers. Recent evidence indicates that the average Filipino rice farmer is only $40 \%$ as efficient as the best-performing Filipino farmer (Villano and Fleming, 2006). Shortfalls in managerial performance can be a major socioeconomic constraint particularly in developing countries (Bravo-Ureta et al., 2007). On average, most rice farmers in the Philippines would benefit from additional skills in order to enhance the profitability of their rice farming enterprises. The relatively low fertiliser use and improper timing of applications, accompanied by poor management practices, are major sources of inefficiency (Sebastian et al., 2000). In addition, limited access to credit for processing and storage facilities forces farmers to sell their marketable surplus during harvest months when prices are low. Farmers are unable to wait for a good price because they do not have adequate places to dry and store their rice and as a result wholesalers dictate prices to retailers and consumers. Institutional and policy constraints, including government policies, rice price-setting mechanisms, credit and input supply, land tenure, marketing development and extension, are also vital. Technical constraints such as limitations on varieties planted, resource-use efficiency (water, soil, nutrients, seed quality and pest and weed control), and harvest and post-harvest activities also pose important challenges to productivity growth (Sebastian et al., 2000).

Considerable efforts have been made to explain the various factors that cause differences in rice yields and these studies have been motivated primarily by the need to find ways to close the so-called 'yield gap' (Neuman et al., 2010; Laborte et al., 2012). The yield gap is the difference between the potential and observed average farm yields over some specified spatial and temporal scale of interest (Lobell et al., 2009). This concept is frequently used in technical agronomic analysis of production as a measure of performance because it implies a comparison between yields actually obtained under particular agroecological conditions on commercial farms and the maximum or potential yield in that region (Nin-Pratt et al., 2011). Yields are used as a measure of productivity and narrowing the gap is frequently singled out as a key to increasing resource use efficiency and thereby production and productivity. Major efforts have been made to develop improved seeds focusing particularly on drought- and flood-tolerant varieties that can withstand adverse soil and climatic conditions (Makarim, 2000; Mueller et al., 2012; Saito et al., 2012). Analysts have also looked at the impact of technology adoption and diffusion on smallholder productivity (e.g. Chirwa, 2005; Mariano et al., 2012).

\section{Review of Literature on Technology Adoption and TFP Growth in Philippine Rice Production}

The importance of rice in rural development in the Philippines and other Asian countries has prompted economists to measure changes in productivity and efficiency since the introduction of Green Revolution production technologies in the 1960s (Mariano et al., 2011). Farmers in the Philippines have made significant progress, but two main concerns have emerged in the rice sector that have cast doubt on the sustainability of the early advances in TFP in the post-Green Revolution era. First, a slowdown (and even a reversal) in TFP growth has been reported in various recent studies. Tiongco and Dawe (2002) showed that after correcting for exogenous yield shocks, the longterm productivity of intensive rice cropping systems in the Philippines stagnated during the early 1980s to the mid-1990s. Umetsu et al. (2003) measured technical 
efficiency (TE) and technological progress in rice production in the Philippines over the 20-year period from 1971 to 1990 and reported positive changes in TE in the first 10 years (1971-80) but a decline from 1981 to 1990 . Technological progress was evident from the mid-1970s to the mid-1980s while the rest of the study period showed regress. Yao and Shively (2007) undertook a more specific evaluation of technological progress and TE for irrigated rice production in the Philippines and found that the management of irrigation water plays a crucial role in productivity. Bordey and Nelson (2012) employed growth accounting to examine the patterns and sources of productivity in rice production in the Philippines for the period 1996-2007. They decomposed output growth into changes in conventional and non-conventional inputs, and a remainder non attributable to inputs known as residual TFP. Their analysis was conducted for two time periods per cropping season, 1996-2001 and 2001-06 for the wet season, and 1997-2002 and 2002-07 for the dry season. The authors found higher output growth rates during the wet and dry seasons of 2001-06 and 2002-07 compared to 1996-2001 and 1997-2002. Wet season rice output grew by $22 \%$ from 2001 to 2006 , of which $15 \%$ and $6 \%$ were attributed respectively to increases in the use of conventional and non-conventional inputs with a residual TFP growth of $1 \%$. On the other hand, rice output grew by $14 \%$ from $2002-07$ of which $10 \%$ was due to increases in non-conventional inputs and $4 \%$ to residual TFP. Mariano et al. (2010) suggest that farms in the rainfed farming ecosystem achieve productivity levels only slightly different from those in the irrigated farming ecosystem. Using the same dataset, Mataia et al. (2011) found that the main factors contributing to rice yield growth in the Philippines from 1997 to 2007 were the adoption of high quality seeds and irrigation.

Second, several production frontier studies have analysed rice farming in the Philippines and the results have been mixed, depending on the region and period of analysis and the production environments. However, these studies typically reveal substantial gaps between the best-performing producers and other producers, with a range of technical efficiency estimates from 0.38 to 0.95. Kalirajan and Flinn (1983) studied rice production in the Bicol region, and obtained TE estimates ranging widely from 0.38 to 0.91. Dawson and Lingard (1989) measured the TE of rice farmers in Central Luzon during the period $1970-85$ and found a much tighter range going from 0.84 to 0.95. In a dataset collected from Central Luzon, Western Visayas, Central Mindanao, Bicol and the Cagayan Valley regions for the period 1987-90, Rola and QuintanaAlejandrino (1993) observed lower mean TEs of 0.72, 0.65 and 0.57 for irrigated, rainfed and upland ecosystems, respectively. Villano and Fleming (2006) obtained a mean TE of 0.79 for the 1990-97 period using rainfed rice data from Central Luzon. On the other hand, Pate and Cruz (2007) reported relatively high mean TEs equal to 0.92 and 0.90 for irrigated and rainfed rice production, respectively, between 1991 and 2002. These estimates clearly suggest that many rice producers in the country are operating well below 'best practice', hence, additional efforts to investigate these productivity gaps are justified given the implications for interpersonal income inequalities within the rural population.

Mariano et al. (2010) suggest that the adoption and diffusion of appropriate technologies can narrow the technology gap that exists within and between the various farming ecosystems in the Philippines. An option to increase productivity is to adopt high quality certified seeds, the centrepiece of the Green Revolution technology package and one of the main products of rice research, which have contributed around 10$20 \%$ of the growth in rice production (Balisacan et al., 2006; Bordey and Nelson, 
2012). Research has shown that the adoption of modern rice technologies is influenced by several factors, including demographic, farm and bio-physical characteristics (Mariano et al., 2012). Gonzales et al. (2007), Manalili et al. (2008) and Malasa and Velayo (2009) analysed the adoption levels of certified inbred and hybrid seed technologies and found that the yields and profitability of technology adopters are higher than those of non-adopters.

\section{Analytical Framework}

The main motivation of this study is to disentangle the effects of technology and managerial ability on the productivity of rice farmers. In doing so, we employ a multi-stage procedure in order to control for biases from observables and unobservables and address some of the shortcomings in previous studies. First, propensity score matching (PSM) is used to select a sample of adopters and nonadopters of CSs with comparable time-invariant characteristics, so as to control for biases from observables. Then, stochastic production frontiers (SPFs) corrected for sample selection are estimated to measure productivity and TE levels for both groups of farmers while controlling for biases from unobservables. Third, metafrontiers are used to offer a comparison of the impact of CSs on productivity and TE by providing a common technology of reference for both adopters and nonadopters.

\subsection{Propensity score matching (PSM)}

To mitigate biases coming from observables, we use PSM to create a suitable counterfactual dataset. The use of PSM makes it possible to match farmers who adopt CSs with those who do not based on observed time-invariant characteristics so that both groups are as similar as possible except for adoption. Recent applications of PSM in agriculture include Pufahl and Weiss (2009), Wu et al. (2010), Bravo-Ureta et al. (2011), Cavatassi et al. (2011) and Rejesus et al. (2011).

To implement PSM, a binary choice model is used to generate a 'propensity score' (PS) for each farm in the sample. These scores represent the probability of being an adopter, considering both adopter and non-adopter farmers, based on a set of covariates (Becker and Ichino, 2002; Cameron and Trivedi, 2005; Imbens and Wooldridge, 2008). The PSs are then used to match adopters with non-adopters for those farms falling within a 'common support' area whereby observations from adopters with a PS smaller than the minimum or larger than the maximum for the non-adopter group are removed from the sample (Caliendo and Kopeinig, 2008). To ensure that the samples within the common support area have the same distribution of observable characteristics, regardless of whether the farmer has adopted the technology or not, it is necessary to test for the 'balancing property' (Becker and Ichino, 2002). Once appropriately matched samples are identified, and assuming that there are no biases from unobservables, the impact of an intervention/adoption is often measured as the average treatment effect on the treated or ATET (Khandker et al., 2010). The ATET is the average impact of the treatment on those individuals who participated and, again assuming no selection bias, can be calculated as (Winters et al., 2010):

$$
A T E T=E\left(Y_{1} \mid D=1\right)-E\left(Y_{0} \mid D=0\right)
$$


where $Y_{1}$ and $Y_{0}$ are the average values of the indicator in question, e.g. output, for treated and non-treated farmers, respectively, and $D$ is a dummy variable equal to 1 if the farmer received the treatment, and 0 if the farmer did not (i.e. control).

\subsection{Stochastic production frontiers $(S P F)$ and sample selection}

SPF methods have been used extensively in many industries, including agriculture, to model input-output relationships and measure the efficiency of individual producers (Battese, 1992; Bravo-Ureta and Pinheiro, 1993; Bravo-Ureta et al., 2007). These methods have also been used to compare the performance of farmers under different technological interventions. For example, the method has been used to examine the impact of technology adoption versus non-adoption on the predicted output and on the TE of firms (Revilla-Molina et al., 2009; Huelgas and Templeton, 2010; Mariano et al., 2012). The limitation of most studies that have used SPFs to compare the TE of adopters versus non-adopters is the failure to account for selectivity biases arising from both observable and unobservable variables in a manner that is compatible with the nonlinear nature of the SPF approach.

Following Heckman's (1979) methodology to account for selection bias, several attempts have been made to address sample selection in a stochastic frontier framework. Sipilainen and Oude Lansink (2005) added an inverse Mill's ratio (IMR) to the deterministic part of the frontier function to examine possible sample selection bias in the analysis of organic and conventional farms. A similar approach was implemented by Solís et al. (2007) when analysing farmers with different levels of adoption of soil conservation in Central America. However, this procedure has proven unsuitable for nonlinear models such as the SPF (Greene, 2010). In recent years, alternative strategies have been proposed to deal with this problem including the one by Kumbhakar et al. (2009) who developed a model where the selection mechanism is assumed to operate through the one-sided error in the frontier, and then used their model to evaluate the performance of organic versus conventional dairy farming in Finland. Lai et al. (2009) studied wage determination employing a copula function and assumed that selection is correlated with the composed error in the frontier. These two models require computationally demanding log likelihood functions.

In this study we adopt the framework developed by Greene (2010) who extended Heckman's approach to consider sample selection in a stochastic frontier framework assuming that the unobserved characteristics in the selection equation are correlated with the noise in the stochastic frontier. The model introduced by Greene can be expressed succinctly with the following three blocks of equations:

$$
\begin{gathered}
\text { Sample selection: } d_{i}=1\left[\alpha^{\prime} z_{i}+w_{i}>0\right], w_{i} \sim N(0,1) \\
\text { Stochastic frontier model: } y_{i}=\beta^{\prime} x_{i}+\varepsilon_{i} \\
\left(y_{i}, x_{i}\right) \text { are observed only when } d_{i}=1 \\
\text { Error structure: } \varepsilon_{i}=v_{i}-u_{i} \\
u_{i}=\left|\sigma_{u} U_{i}\right|=\sigma_{u}\left|U_{i}\right| \text { where } U_{i} \sim N(0,1) \\
v_{i}=\sigma_{v} V_{i} \text { where } V_{i} \sim N(0,1)
\end{gathered}
$$




$$
\left(w_{i}, v_{i}\right) \sim N_{2}\left[(0,0),\left(1, \rho \sigma_{v}, \sigma_{v}^{2}\right)\right]
$$

where $d$ is a binary variable equal to one for adopters, and zero for non-adopters, $z$ is a vector of explanatory variables included in the (binary) sample selection model and $w_{i}$ is the unobservable error term. Furthermore, $y$ is output, $\boldsymbol{x}$ is a vector of inputs in the production frontier and $\varepsilon$ is the composed error term. The coefficients $\alpha$ and $\beta$ are parameters to be estimated while the elements in the error structure correspond to those typically included in the stochastic frontier formulation. In this model, sample selection arises if the noise in the stochastic frontier, $v_{i}$, is correlated with unobserved characteristics in the sample selection equation, $w_{i}$ (Greene, 2010). A statistically significant $\rho$ is evidence that selectivity bias in unobservables is present. Readers interested in the full model and details concerning its estimation are referred to Greene (2010) and Bravo-Ureta et al. (2012).

\subsection{Meta-frontier}

A limitation of the methodological framework described above is that a direct comparison of TE between adopters and non-adopters is not possible because these scores are relative to each group's own frontier (González-Flores et al., 2014). To address this issue we estimate meta-frontiers for the preferred model as discussed below. Following the approach outlined by O'Donnell et al. (2008), we estimate a meta-frontier that envelops the deterministic component of the adopter and non-adopter group frontiers. This enables the estimation of the gaps between the meta-frontier and the individual group frontiers, termed the meta-technology ratio (MTR). O'Donnell et al. (2008) define the meta-frontier enveloping the deterministic component of the individual group frontiers $(j)$ as:

$$
y_{i}^{*}=f\left(x_{i}, \beta^{*}\right)=e^{x_{i} \beta^{*}}
$$

where $y^{*}$ is the meta-frontier output, $\beta^{*}$ denotes the vector of parameters such that $x_{i} \beta^{*} \geq x_{i} \beta_{j}$ and $\beta_{j}$ are parameters obtained from the adopter and non-adopter group frontiers. For given levels of inputs, the meta-technology ratio is calculated as the ratio of the highest attainable group output to the highest possible meta-frontier output and is therefore an index lying between zero and unity, defined as:

$$
M T R=\frac{e^{x_{i} \beta_{j}}}{e^{x_{i} \beta^{*}}} .
$$

TE with respect to the meta-frontier is then calculated as:

$$
T E_{M}=T E_{j} \times M T R_{j} .
$$

\section{Data and Empirical Model}

As indicated above, we follow the approach of Greene (2010) and Bravo-Ureta et al. (2012) where the PSM and SPF approaches are combined in order to correct biases from both observed and unobserved characteristics. The intention is to obtain unbiased estimates of the coefficients of the production frontier in rice farming to then measure TE as an indicator of managerial gaps as well as any shifts in the frontiers due to the adoption of improved seed varieties that can be interpreted as technological progress (Anderson and Feder, 2007). 
We use cross-sectional data collected for 3,164 rice-farming households in the Philippines for the agricultural year 2006-07 covering two cropping seasons. There are 1,941 observations in the wet season of 2006 (from late June to October) and 1,223 in the 2007 dry season (from late December to April). A total of 952 farmers in the sample (590 for the wet season and 362 for the dry season) are considered adopters of CSs while the remaining 2,212 are non-adopters. We pool the data for the wet and dry seasons and capture the possible differences between them via seasonal intercept and slope dummy variables in both the CS choice and production frontier models. Pooling of the data across seasons is justified given that factors of production are similar and all technologies and intervention programmes are available to farmers in both seasons.

The data used in this study are derived from the Rice Based Farm Household Survey conducted by PhilRice covering 30 provinces that account for $70 \%$ of the rice produced in the Philippines. The data include information for farmers coming from different agro-ecosystems (rainfed and irrigated) and agroclimatic conditions. Details on the sampling procedure can be found in Mariano et al. $(2010,2011)$.

Several variables are used to implement the combined PSM and SPF procedures. Following Mariano et al. (2012), we include demographic, farm and biophysical characteristics in estimating the probit model used for the PSM. Descriptions of these variables are presented in Table 1. Model specification is based both on data availability as well as theoretical and empirical foundations coming from the literature.

There are several matching criteria that can be used in implementing PSM (see Cameron and Trivedi, 2005) and here we employ two alternatives, the nearest-neighbour and kernel. For the nearest neighbour procedure, a maximum of five matches per adopter along with a caliper (or maximum tolerance) of 0.025 is used. We apply a trimming procedure to establish the region of common support which is defined by the area where there is positive density within the $d=1$ and $d=0$ distributions (Smith and Todd, 2005). The region of common support for the estimated PSs is the interval between 0.06 and 0.87 and the density of the common support region is presented in Figure 1. The procedure yielded a total of 2,678 matched observations, 772 for adopters and 1,906 for non-adopters. We also employed an Epanechnikov kernel matching (Greene, 2007; Guo and Fraser, 2010) with bandwidth of 0.06 that yielded a total of 3,141 matched observations. However, a comparison of means revealed that the nearest neighbour option yielded better-matched samples; hence; the analysis below is based on the samples obtained with this method.

After completing the matching procedures, comparisons of means for the variables are undertaken. As shown in Table 2, the data indicate that there is no significant difference between the means of observable characteristics of adopters and non-adopters after matching, thus fulfilling the balancing condition of the covariates (Leuven and Sianesi, 2003; Rejesus et al., 2011). By contrast, the means are significantly different for most of the variables using the unmatched samples.

Once the sample of adopters and non-adopters is matched, we estimate SPFs correcting for sample selection that might arise from the choice to adopt CSs. We assume that farmers adopt the technology in order to maximise the expected profits from rice production, and that the decision by farmers to adopt the CS technology can be explained by demographic, social and bio-physical characteristics. In general, the sample selection model can be expressed as: 
Table 1

Description of variables used in the PSM and SPF models

\begin{tabular}{|c|c|c|}
\hline Variables & Notation & Definition \\
\hline \multicolumn{3}{|l|}{ Probit Model } \\
\hline \multicolumn{3}{|l|}{ Farmer characteristics } \\
\hline Gender & $Z_{1}$ & 1 if the farmer is male, 0 otherwise \\
\hline Schooling & $Z_{2}$ & $\begin{array}{l}\text { Number of years of formal education } \\
\text { by the farmer }\end{array}$ \\
\hline Experience & $Z_{3}$ & Years of rice farming experience of the farmer \\
\hline Household size & $Z_{4}$ & Number of family members \\
\hline \multicolumn{3}{|l|}{ Farm assets/resources } \\
\hline Cultivated area owned & $Z_{5}$ & Percentage of area owned to total area cultivate \\
\hline Machinery ownership & $Z_{6}$ & $\begin{array}{l}1 \text { if the farmer owns any tractor or harvester, } \\
0 \text { otherwise }\end{array}$ \\
\hline Non-rice income & $Z_{7}$ & $\begin{array}{l}\text { Total income from sources other than rice } \\
\text { farming in thousands of Philippine pesos }(\mathrm{P})\end{array}$ \\
\hline \multicolumn{3}{|l|}{ Institutional factors } \\
\hline Farm size & $Z_{8}$ & Total rice area planted in hectares \\
\hline Credit access & $Z_{9}$ & 1 if the farmer has access to credit, 0 otherwise \\
\hline \multicolumn{3}{|l|}{ Extension } \\
\hline On-farm demonstrations & $Z_{10}$ & $\begin{array}{l}1 \text { if the farmer participated in any on-farm } \\
\text { demonstrations, } 0 \text { otherwise }\end{array}$ \\
\hline Attendance at training sessions & $Z_{11}$ & $\begin{array}{l}1 \text { if the farmer attended any rice production } \\
\text { training sessions, } 0 \text { otherwise }\end{array}$ \\
\hline Access to extension workers & $Z_{12}$ & $\begin{array}{l}1 \text { if the farmer has access to advice from } \\
\text { extension workers, } 0 \text { otherwise }\end{array}$ \\
\hline \multicolumn{3}{|l|}{ Biophysical conditions } \\
\hline Sufficient water for irrigation & $Z_{13}$ & $\begin{array}{l}1 \text { if the farmer has an adequate source of } \\
\text { water for irrigation, } 0 \text { otherwise }\end{array}$ \\
\hline NPK deficiency & $Z_{14}$ & $\begin{array}{l}1 \text { if the farmer's field is nutrient-deficient, } \\
0 \text { otherwise }\end{array}$ \\
\hline Drought-prone area & $Z_{15}$ & $\begin{array}{l}1 \text { if the farmer's field is prone to drought, } \\
0 \text { otherwise }\end{array}$ \\
\hline Submergence-prone area & $Z_{16}$ & $\begin{array}{l}1 \text { if the farmer's field is prone to water } \\
\text { submergence, } 0 \text { otherwise }\end{array}$ \\
\hline \multicolumn{3}{|l|}{ SPF Model } \\
\hline Output & $Y$ & $\begin{array}{l}\text { Dependent variable: total production of } \\
\text { rice in kilograms }\end{array}$ \\
\hline Area & $X_{1}$ & Total rice area planted in hectares \\
\hline Seed & $X_{2}$ & Seed used in kilograms \\
\hline Fertiliser & $X_{3}$ & Total NPK (kilogram of active ingredient) \\
\hline Chemical & $X_{4}$ & Total active ingredients of chemical used ( $\mathrm{kg}$ ai) \\
\hline Labour & $X_{5}$ & $\begin{array}{l}\text { Total labour used in rice production } \\
\text { (worker-days) }\end{array}$ \\
\hline Power & $X_{6}$ & Cost of power, including rental and fuel cost $(\mathrm{P})$ \\
\hline Seed quality dummy & $D_{1}$ & 1 if adopter of certified seeds, 0 otherwise \\
\hline Power source dummy & $D_{2}$ & $\begin{array}{l}1 \text { if used machine/tractor as source of power, } \\
0 \text { otherwise }\end{array}$ \\
\hline Fertiliser dummy & $D_{3}$ & 1 if did not apply fertiliser, 0 otherwise \\
\hline Season dummy & $D_{4}$ & 1 if wet cropping season, 0 otherwise \\
\hline
\end{tabular}




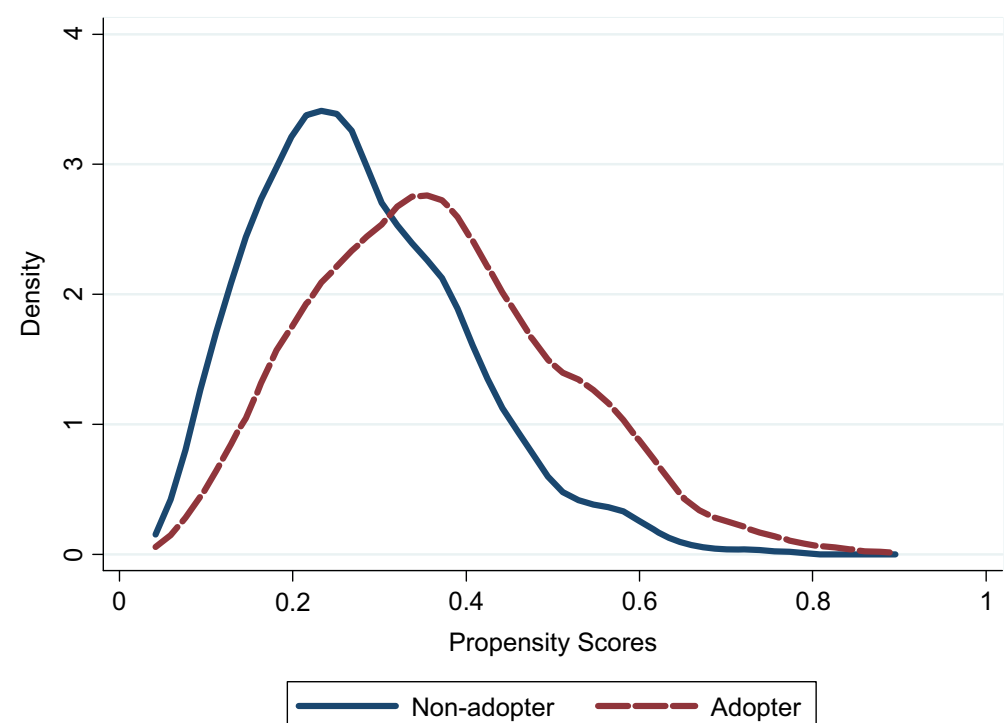

Figure 1. Density of the propensity scores for adopters and non-adopters of certified seeds

$$
\text { adopt }_{i}=\alpha_{0}+\sum_{j=1}^{16} \alpha_{i j} Z_{i j}+w_{i}
$$

where adopt is a dichotomous variable equal to 1 for adopters, $Z$ is a vector of exogenous variables explaining the decision of farmers to adopt the CS technology, $\alpha$ are unknown parameters, and $w$ is the disturbance term distributed as $N\left(0, \sigma^{2}\right)$.

The two most common functional forms used for production frontiers in efficiency studies are the Cobb-Douglas (CD) and translog (TL) (Bravo-Ureta et al., 2007). The TL, which nests the CD, can be written as (Coelli et al., 2003):

$\ln \left(Y_{i}\right)=\beta_{0} \sum_{j=1}^{6} \beta_{j} \ln X_{i j}+\frac{1}{2} \sum_{j=1}^{6} \sum_{j=1}^{6} \beta_{j k} \ln X_{i j} \ln X_{i k}+\sum_{j=1}^{4} \delta_{l} D_{l}+\sum_{j=1}^{6} \gamma_{j} D_{4} \ln X_{i j}+v_{i}-u_{i}$

where $Y_{i}$ represents output of the $i^{\text {th }}$ farm; $X_{i j}$ is the quantity of the $j^{\text {th }}$ input; $D$ denotes dummy variables; $\beta$ and $\delta$ are unknown parameters; and $v$ and $u$ are the elements of the composed error term, $\varepsilon$. A maximum likelihood ratio test led to the rejection of the CD functional form in favour of the translog. ${ }^{3}$ The dependent variable in the estimated SPF model is total rice production in kilograms of paddy rice. The explanatory variables comprise six conventional inputs and four dummies. The conventional inputs include area planted with rice (in hectares), quantity of seeds used (in kilograms), nitrogen, phosphorus and potassium (NPK) expressed as the quantity of active ingredients applied (in kilograms), amount of active ingredients (AIs) used for

\footnotetext{
${ }^{3}$ Zero inputs are handled using the methodology proposed by Battese (1997) whereby the logarithm of the input variable with zero values, such as fertiliser, is taken only if it is positive, otherwise the variable is zero. Accordingly, a dummy variable to take into account those zero values is included in the model, e.g. $D_{3}$.
} 


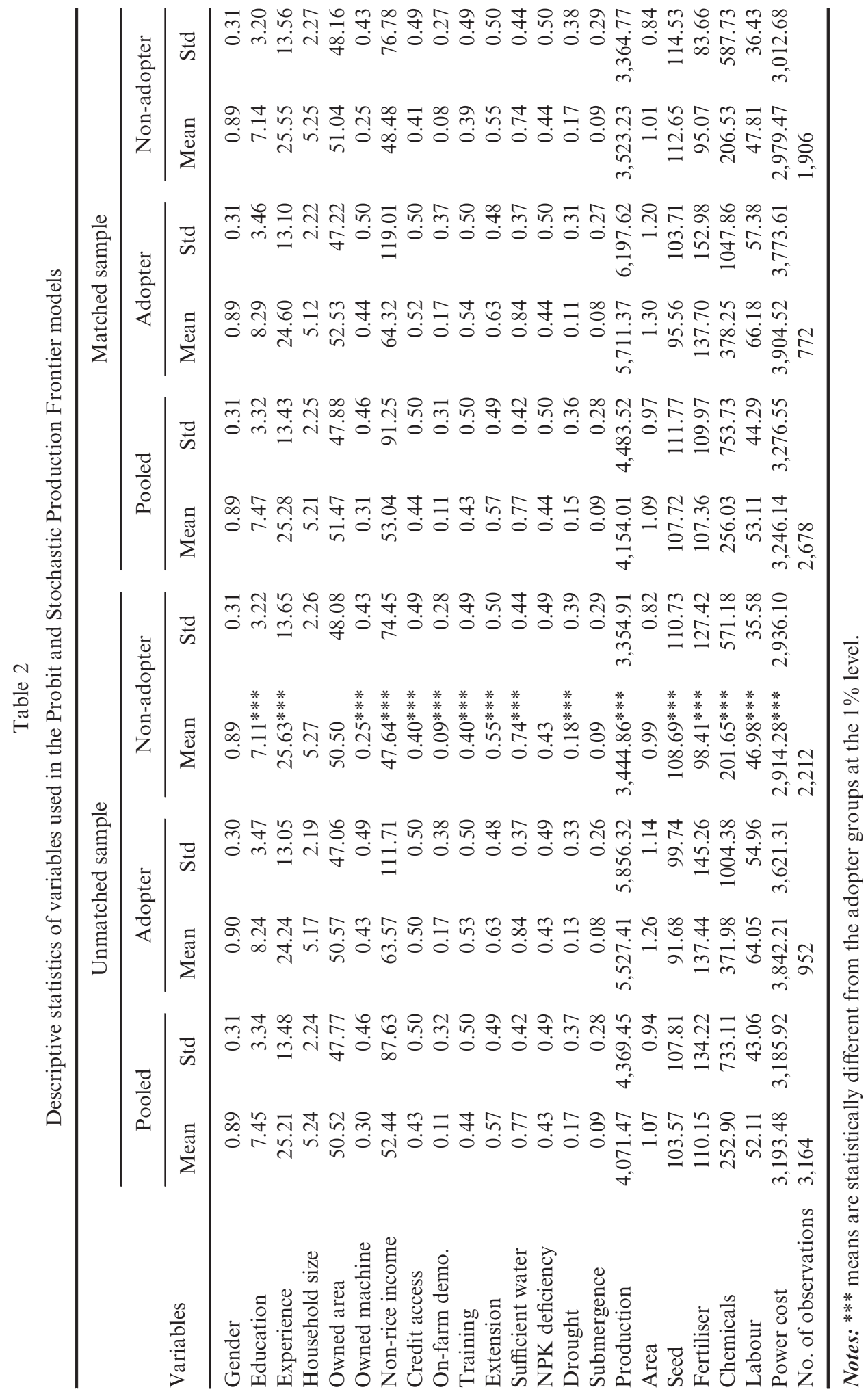


herbicides and insecticides (in kilograms), total labour used in farm activities (in worker-days), and the machine rental cost for land-preparation and threshing activities (in 2007 Philippine pesos, P). The four dummy variables are: seed quality $\left(D_{1}=1\right.$ if the farmer used CS); source of power $\left(D_{2}=1\right.$ if the farmer used a tractor in land preparation or a thresher in harvesting activities); fertiliser usage $\left(D_{3}=1\right.$ to account for those farmers who did not use fertiliser); and cropping season $\left(D_{4}=1\right.$ for wet season, and 0 otherwise).

To reiterate, our goal is to identify the impact of CS adoption on two components of productivity: (1) technological change, captured as a shift in the frontier due to adoption; and (2) managerial performance, measured by TE scores. The estimation process is summarised as follows. First, all available data are used to estimate a probit model to calculate PSs, which are the basis for matching adopters and non-adopters and thus correct for biases from observed characteristics. Second, a pooled SPF model is estimated where the binary variable adopt ( 0 for non-adopters, 1 for adopters) is included as a regressor to account for technological change attributable to the adoption of CS. Third, two separate SPF models are estimated using the matched subsamples, one for adopters and the second for non-adopters without correction for selectivity bias. Thus, these models correct only for biases from observables. Fourth, two separate selectivity-corrected SPFs are estimated, one for adopters and the other for non-adopters, and these models correct for biases from both observed and unobserved variables. For comparison purposes, separate models are estimated for adopters and non-adopters using the unmatched data, which ignores biases from both observables and unobservables. Various hypotheses are evaluated using log-likelihood ratio tests. All models are estimated using NLOGIT Version 4.0 (Greene, 2007).

\section{Results and Discussion}

\subsection{Determinants of CS technology adoption}

Several studies have examined the factors explaining the adoption of modern technologies in the agricultural sector in general (e.g. Feder et al., 1985) and the rice sector in particular (e.g. Joshi and Pandey, 2004; Estudillo and Otsuka, 2006; and Mariano et al., 2012). Mariano et al. (2012) used a logit model to examine the determinants of modern rice technologies in the Philippines. Here, we revisit the estimates of factors affecting the adoption of CS technology using the sample selection model. Following equation (6), the results of a probit sample selection model using matched samples are presented in Table 3. The chi-squared test statistics are significant at the $1 \%$ level, which implies the joint significance of the parameters for the CS adoption variables. Among the variables representing farmer characteristics, education and household size are significant factors in the choice of CS technology. As expected, farmers who are better educated have greater ability to process information and search for technologies suitable to their production constraints than those who are less educated (Mariano et al., 2012). Moreover, in a recent survey of microeconomic studies of technology adoption, Foster and Rosenzweig (2010, p. 421) conclude that '. . . education plays an important role in facilitating the acquisition and processing of new information, which appears to account for the pervasive finding that more educated agents adopt new technologies first'.

The variable household size is inversely related to technology adoption at the $1 \%$ significance level, suggesting that large households are more risk averse than smaller 
Table 3

Estimates of the Probit selection equation using matched samples

\begin{tabular}{lcc}
\hline Variables & Coefficient & Standard error \\
\hline Constant & $-1.300^{* * *}$ & 0.160 \\
Gender (\% male) & -0.027 & 0.086 \\
Schooling (years) & $0.043^{* * *}$ & 0.009 \\
Experience (years) & -0.002 & 0.002 \\
Household size (count) & $-0.032^{* * *}$ & 0.012 \\
Area cultivated owned (\%) & -0.00060 & 0.00057 \\
Machine owner (\%) & $0.397^{* * *}$ & 0.061 \\
Non-rice income (000 Philippine pesos) & $0.00058^{*}$ & 0.00030 \\
Farm size (ha) & $0.065^{* *}$ & 0.029 \\
Credit access (\%) & $0.222^{* * *}$ & 0.055 \\
Attendance at training (\%) & $0.224^{* * *}$ & 0.055 \\
Participation in on-farm demo. (\%) & $0.314^{* * *}$ & 0.083 \\
Access to extension workers (\%) & $0.134^{* * *}$ & 0.055 \\
Sufficient water irrigation (\%) & $0.246^{* * *}$ & 0.070 \\
NPK deficiency (\%) & -0.084 & 0.059 \\
Drought-prone area (\%) & $-0.215^{* *}$ & 0.087 \\
Submergence-prone area (\%) & $-0.198^{*}$ & 0.086 \\
Log-likelihood function & $-1,478.58$ & \\
Chi-squared test statistic & $259.65^{* * *}$ & \\
Number of observations & 2,678 & \\
\hline
\end{tabular}

Notes: $* * *, * *, *$ Significant at $1 \%, 5 \%$ and $10 \%$ levels, respectively. The standard errors of the coefficients are correct to two significant digits, and the respective coefficients are correct to corresponding digits behind the decimal point.

households. Resource ownership and higher household income are expected to encourage the adoption of modern technologies (Mariano et al., 2012), yet our results diverge from these expectations.

The coefficient on the variable for owned cultivated area is negative but not significant. This result is consistent with the presence of countervailing factors determining whether farmers who rent land will be more likely to adopt the CS technology than those who cultivate their own land. For farmer-tenants, a larger harvest from the adoption of CSs leads to greater output, revenue and profits, but the extent of the additional profits they retain depends on their contractual arrangement with landowners. Output is shared by tenants with their landlord in a crop-share contract but is fully retained in a fixed-rent contract. We would expect that a larger output means a larger share for tenant farmers in a crop-share arrangement, but owner-farmers keep all additional profits from adoption and so they should adopt more rapidly. On the other hand, risks are shared between tenants and landowners in a crop-share contract, which may encourage adoption given the uncertain outcomes associated with adopting new technologies.

Farmers who own labour-saving assets, such as a tractor, are more likely to adopt $\mathrm{CS}$ technology. Income from non-rice activities is also found to have a significant positive effect on the decision to adopt the CS technology. All institutional factors included in the model are found to be significant determinants of adoption. Because seed inputs are perfectly divisible, farmers who own large areas of land can spread the 
risk of technology failure by allocating only a portion of their land to CSs, an option that is not available to the same extent to farmers who own only a small area of land. As expected, the effect of access to credit is significant because the use of CSs requires additional cash for purchased inputs such as fertiliser and pesticides. Availability of and access to credit is expected to promote the decision to adopt improved technologies such as CSs. There is considerable survey-based evidence showing that farmers in developing economies would be willing to borrow more if additional credit was made available at a given interest rate, which suggests that credit rationing is indeed an issue (Conning and Udry, 2007). Our results also highlight that farmers who attend training sessions, who participate in on-farm demonstrations and who have access to extension workers are more likely to adopt CS. This finding is consistent with many studies where extension plays a significant role in the adoption of modern technologies (e.g. Jara-Rojas et al., 2012; Mariano et al., 2012).

Adoption of CS technologies is also influenced by bio-physical and environmental characteristics. As expected, having sufficient irrigation water has a positive influence on CS adoption. Farms that are well irrigated have lower risk of crop failure due to lack of moisture, enhancing the appeal of investment in the technology. Drought and submergence prone areas are two biophysical variables that have a negative effect on the adoption of CSs. In addition, NPK deficiency exhibits a negative but non-significant coefficient, which is consistent with the notion that this deficiency is easier to remedy through the application of appropriate fertilisers compared to submergence and drought, which might require significant investments in infrastructure and technological improvements. Nevertheless, the introduction of new rice varieties can relax this investment constraint. For example, a variety such as Submarino 1 can withstand being under water for 2-3 weeks and has been promoted aggressively by various government agencies to rice farmers. Details of the marginal effects of variables affecting adoption of CS technology based on a similar model and data as the one used here can be found in Mariano et al. (2012).

\subsection{Production technology estimates}

The maximum likelihood estimates of the conventional and selectivity-corrected SPFs using the matched samples are presented in Table 4. All variables in the translog models were normalised by their corresponding geometric means so the first-order coefficients can be interpreted as partial elasticities of output with respect to inputs at mean values (Coelli et al., 2003).

In order to examine the productivity differences between adopters and non-adopters of CS technology, we conducted two sets of hypothesis tests. First, we found significant differences between the mean outputs of adopters and non-adopters, with $t$-ratios of $6.69(P$-value $=0.000)$. Second, using a likelihood ratio test, we examined if there are technology differences between the two groups. We tested the null hypothesis that there is no difference between the pooled frontier model and the two group frontiers. With a generalised likelihood ratio test statistic of $103.92(P$-value $=0.000)$, the null hypothesis is rejected suggesting significant technology differences between adopters and non-adopters; thus, estimation of separate frontiers for each group is justified.

Estimation of the selectivity-corrected SPF model shows that the selectivity coefficient, $\rho$, is significantly different from zero for both adopters and non-adopters, which suggests that selection bias is a relevant consideration in this analysis. Thus, the use of 


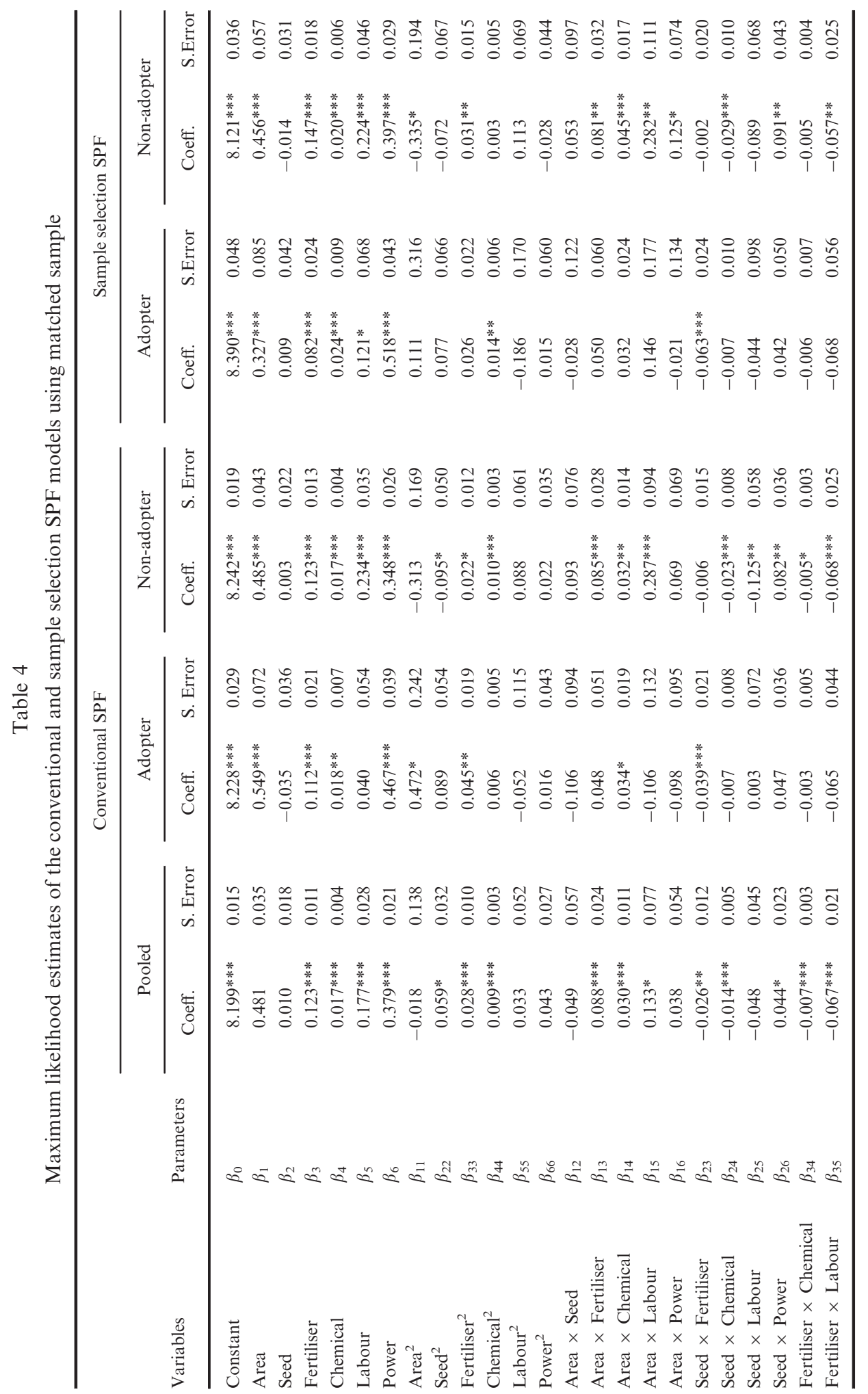




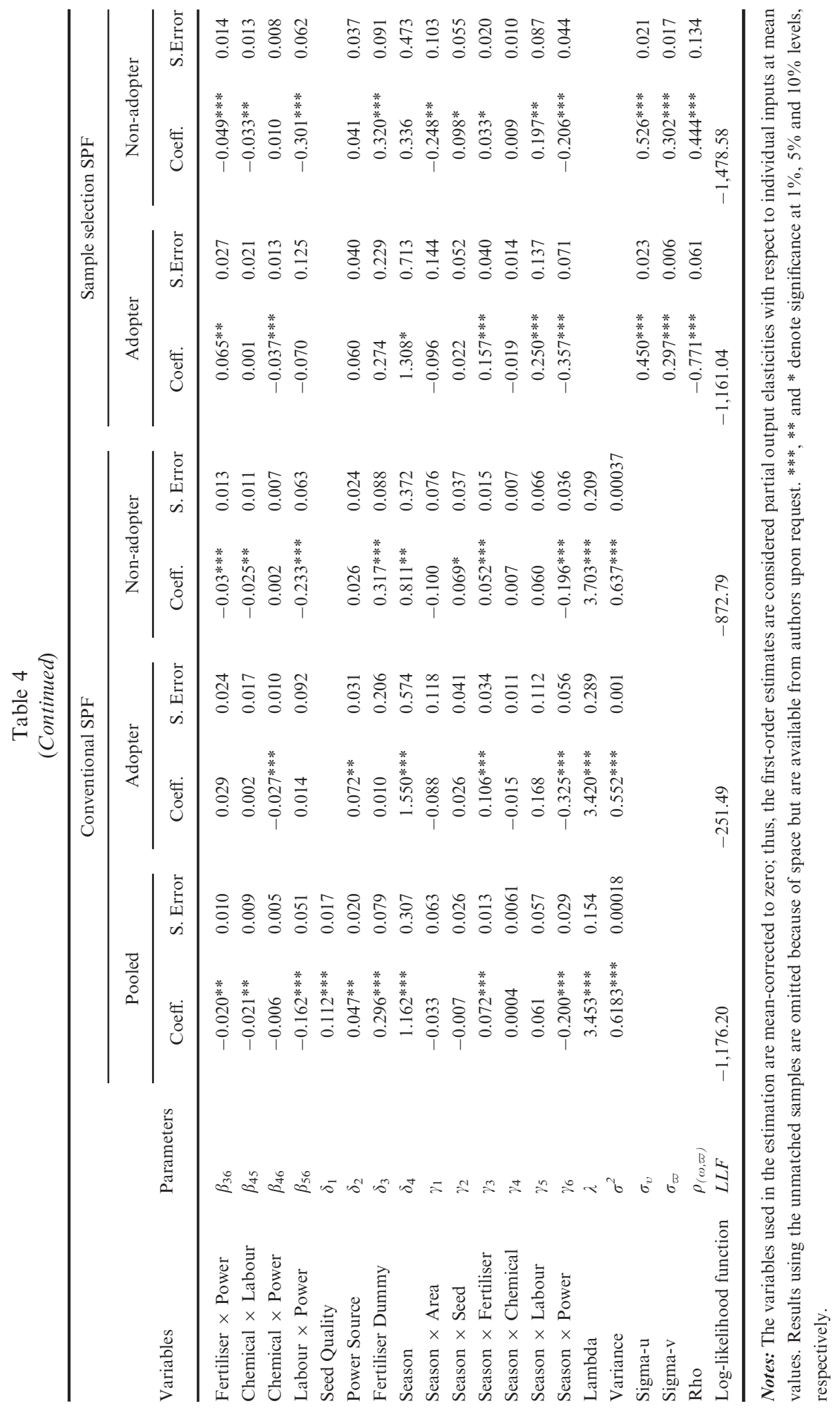


the SPF within a sample selection framework to estimate separate SPFs for adopters and non-adopters is justified. The magnitude of the estimated coefficients for most variables is lower for the selectivity-corrected SPF models compared with the estimates from the conventional frontiers suggesting that sample selection bias has resulted in overestimated average partial elasticities. Also, the presence of selection bias implies that the estimates from conventional SPFs are biased and thus lead to inaccurate TE scores (Rahman et al., 2009; Bravo-Ureta et al., 2012).

Except for the coefficient for the quantity of seed for the non-adopters, the results from the selectivity-corrected SPFs indicate that all estimated linear coefficients for the inputs have the expected positive sign and are significant at least at the $10 \%$ level. These results are consistent with those reported by Villano and Fleming (2006) and Mariano et al. (2010). For adopters, the variable with the highest output elasticity is the use of a machine in rice production activities, while the output for non-CS adopters is most responsive to expansion of the area planted to rice (Table 4).

In Table 4, the parameter estimates for the dummy variables indicate that CS $\left(\delta_{1}\right)$, mechanisation $\left(\delta_{2}\right)$, use of fertiliser $\left(\delta_{3}\right)$ and dry cropping season $\left(\delta_{4}\right)$, all make a positive contribution to rice output. While the parameter for the quantity of seed variable $\left(\beta_{2}\right)$ is not significant, the results do highlight that the type of seed used $\left(\delta_{1}\right)$ plays a crucial role in increasing rice production. Farmers who used CS were found to enjoy about an $11 \%$ output advantage compared with farmers who used their own seeds.

We also found that the dry season is more favourable to rice production than the wet season. Using the results from the selectivity-corrected SPF, we evaluate the interaction of the seasonal dummy variable and input variables. It was surprising that while output is higher during the dry season, the differential decreases as area planted to rice and power cost rise. As expected, the use of fertiliser and labour productivity in the dry season has a significant positive effect on rice production.

\subsection{Efficiency estimates}

The parameter $\lambda$ in Table 4 is found to be significantly different from zero, indicating that inefficiency is an important contributor to total output variability. Accordingly, summaries of TE scores are presented in Table 5. The first sets of TE estimates are from the conventional (TE-Pool and TE-Conventional SPF) and selectivity-corrected SPFs (TE-Sample Selection SPF) models for the matched samples in order to evaluate the efficiency differentials across alternative specifications.

Using the pooled estimates (TE-Pool), it would appear that the mean TE for adopters is not significantly different from that of non-adopters, and the range is also the same going from $37 \%$ to $96 \%$. In order to obtain estimates of TE relative to their cohorts, two sets of TE estimates are obtained: (i) using conventional SPF (TE-Conventional SPF), and (ii) using the sample selection SPF to account for selection bias (TE-Sample Selection SPF). By looking at the individual group frontiers it shows that adopters are performing better within their own cohorts than non-adopters, as evidenced by higher estimates of TE-Conventional SPF ( 0.70 versus 0.67$)$ and TE-Sample Selection SPF (0.73 versus 0.69), respectively. While these estimates cannot be used to compare between groups, they illustrate the importance of tackling selectivity bias. These TE differentials show the presence of a managerial gap between adopters and non-adopters. The effect of correcting for selectivity bias is also reflected in the distribution of TE scores, where the coefficient of variation (standard deviation/mean) 
Table 5

Descriptive statistics of TE scores from alternative models for rice farmers

\begin{tabular}{lccccc}
\hline Item & Mean & St.Dev & Minimum & Maximum & CV $(\%)^{*}$ \\
\hline Adopter $^{\dagger}$ & & & & & \\
TE-Pool $^{\dagger}$ & 0.68 & 0.15 & 0.37 & 0.96 & 21 \\
TE-Conventional SPF $^{*}$ & 0.70 & 0.14 & 0.41 & 0.97 & 20 \\
TE-Sample Selection SPF $^{*}$ & 0.73 & 0.12 & 0.27 & 0.96 & 16 \\
Metatechnology ratio (MTR) $^{\S}$ & 0.90 & 0.11 & 0.36 & 1.00 & 12 \\
$\quad$ TE-Metafrontier & 0.61 & 0.15 & 0.18 & 0.92 & 24 \\
Non-adopter $^{\text {TE-Pool }}$ & & & & & \\
TE-Conventional SPF* & 0.67 & 0.16 & 0.37 & 0.96 & 24 \\
TE-Sample Selection SPF & 0.67 & 0.16 & 0.38 & 0.96 & 24 \\
Metatechnology ratio (MTR) & 0.69 & 0.13 & 0.17 & 0.92 & 18 \\
TE-Metafrontier & 0.54 & 0.23 & 0.10 & 1.00 & 43 \\
& 0.37 & 0.18 & 0.04 & 0.93 & 50 \\
\hline
\end{tabular}

*Coefficient of variation.

TTE estimates using the conventional SPF and the pooled dataset.

TE estimates relative to the individual group's frontier using the conventional SPF.

${ }^{\S} \mathrm{TE}$ estimates relative to the metafrontier.

in TE scores declined from $20 \%$ to $16 \%$ for adopters and from $24 \%$ to $18 \%$ for nonadopters.

In section 6.2 above, we found that there is a statistically significant productivity difference between adopters and non-adopters; thus, we cannot use the individual group frontier's estimates to compare the performance of farmers. In order to make a meaningful comparison across adopters and non-adopters we fitted a meta-frontier based on O'Donnell et al. (2008). For this purpose, we used the estimated parameters from the TL sample selection model specified in equation (7) and fitted the meta-frontier using the linear programming option in SHAZAM. For brevity, and since the variables were adjusted to have zero means, the first-order coefficients and estimates for the dummy variables of the meta-frontier are given as:

$$
\begin{aligned}
\ln \widehat{Y}_{i}= & 8.405+0.351 \ln X_{1}+0.015 \ln X_{2}+0.078 \ln X_{3}+0.023 \ln X_{4}+0.167 \ln X_{5}+ \\
& 0.494 \ln X_{6}+0.069 D_{2}+0.228 D_{3}+1.294 D_{4}-0.124 D_{4} \ln X_{1}+0.007 D_{4} \ln X_{2}+ \\
& 0.165 D_{4} \ln X_{3}-0.022 D_{4} \ln X_{4}+0.222 D_{5} \ln X_{5}-0.315 D_{4} \ln X_{6}
\end{aligned}
$$

This fitted meta-frontier was used to obtain estimates of MTR and TE using equations (4) and (5). A summary of results (MTR and TE-Metafrontier), presented in Table 5, demonstrates unambiguously the risk of ignoring within-sample differences in technology adoption. The estimated mean meta-technology ratio for farmers adopting CSs (0.90) was significantly higher than for farmers who did not adopt CSs (0.54). Consequently, the mean TE relative to the meta-frontier for farmers adopting CSs (0.61) was significantly higher than for non-adopters $(0.37)$.

The analysis of TE scores demonstrates the need to correct for biases from observed and unobserved variables. The empirical results show that without the appropriate corrections, inefficiency was overestimated, while the gap in performance between 
Table 6

Effects of CS technology adoption on key outcome variables

\begin{tabular}{lrcrcc}
\hline Variable & Adopter & Non-adopter & ATET & Standard error & $t$-statistic* \\
\hline Yield (kg/ha) & $4,431.0$ & $3,469.6$ & 961.4 & 63.9 & 15.1 \\
Gross returns (P/ha) & $44,949.3$ & $34,336.0$ & $10,613.3$ & 722.4 & 14.7 \\
Total costs (P/ha) & $20,938.6$ & $18,017.7$ & $2,920.9$ & 389.0 & 7.5 \\
Net returns (P/ha) & $24,010.7$ & $16,318.4$ & $7,692.3$ & 615.5 & 12.5 \\
\hline
\end{tabular}

Notes: * the $t$-statistic is used to test that null hypotheses that there is no difference between the mean of outcome variables for adopter and non-adopter. This is a test for the average treatment effect on treated (ATET) using bootstrapped standard errors.

adopters and non-adopters was underestimated. In the findings reported by Mayen et al. (2010) and Bravo-Ureta et al. (2012) the evidence of bias was the opposite, where the differentials between treated and control units decreased as correction for bias was implemented.

\subsection{Other key outcomes}

The average effects of the CS technology on key outcomes are calculated by comparing output, gross and net returns, and total costs for adopters and non-adopters. The impact of the treatment on the treated (the 'causal effect' of technology adoption) (ATET) is estimated using the expression presented in equation (1) and the results are presented in Table 6. The average of the difference in the outcomes of the two groups, adopters and non-adopters, is computed using the matched samples (Table 6).

Based on the results presented in Table 6, there is evidence of a statistically significant difference between the outcomes of CS adopters and non-adopters. All of the signs of the ATETs are positive indicating that the outcome variables for adopters are higher than they are for non-adopters. On average, a difference of about P7,692 in net returns per hectare was observed after taking into account biases from observable and unobservable characteristics of farmers. Considering the average rice area of 1.09 hectares per household, this difference translates to approximately P8,385 per household. The average household rice income in 2006/07 was P83,284 (Beronio et al., 2010). ${ }^{4}$ Hence, our analysis shows that the adoption of CS technology has had a positive effect on the well-being of rice farmers amounting to approximately $10 \%$ of the average income of households that produce rice. This result is consistent with earlier studies on the impact of technology adoption in agriculture (Pufahl and Weiss, 2009; Wu et al., 2010; Bravo-Ureta et al., 2011).

Finally, we obtained the predicted outputs of rice at the farm level, average farmer level and frontier level. The least squares estimates of equation (4) were used to obtain the predicted values for average farmers, while the maximum-likelihood estimates

\footnotetext{
${ }^{4}$ According to the 2006 Family Income and Expenditure Survey (FIES), the average household income of the bottom $30 \%$ of the population in the Philippines was P49,000. While this is not an ideal point of comparison, as the survey includes urban and rural households, it clearly shows that even a poor rice farmer in the bottom segments can explore the possibility of improving their household income. A more recent FIES survey showed that the average rural farming household income in 2009 was P94,909.
} 
Table 7

Observed and predicted production of rice $(\mathrm{kg} / \mathrm{ha})$

\begin{tabular}{lcr}
\hline Item & Mean & St.Dev. \\
\hline Adopter & & \\
Observed (farm-level) $^{\text {Predicted (average farmer)* }}$ & 4,403 & 1,594 \\
Predicted (frontier farmer) $^{\dagger}$ & 3,884 & 996 \\
Non-adopter $^{\text {Observed (farm-level) }}$ & 6,242 & 1,300 \\
Predicted (average farmer)* $^{*}$ & & \\
Predicted (frontier farmer) $^{\dagger}$ & 3,470 & 1,436 \\
\hline
\end{tabular}

*Predicted output using ordinary least squares.

$\dagger$ Predicted output using SPF with sample selection.

were used to obtain predicted outputs for frontier farmers. The values presented in Table 7 confirm the presence of clear gaps in rice productivity. We note that the concept of a yield gap has been widely used to examine the performance of a particular production unit by identifying the constraints to production. The yield gaps are attributed by scientists to technology differences and the evidence suggests that large yield gaps for rice still exist under both favourable and less favourable conditions, and that they could be narrowed to achieve productivity gains (e.g. Duwayri et al., 2000). Clearly, two ways to close this gap are to encourage adoption of yield-enhancing technologies and to improve the TE of smallholder rice farmers given their technology.

\section{Conclusions}

Increasing productivity in rice production remains a challenge in the Philippines and the same is true for other major grains and many other countries, particularly as we witness sharp increases in food prices (Anon, 2012). In this study, an emerging framework that combines a selection corrected stochastic production frontier (SPF) model with propensity score matching (PSM) was applied to disentangle the effects of technology and managerial gaps on rice productivity. A group of adopters was matched with non-adopters of CSs using PSM to reduce biases from observed variables. Following Greene (2010) and Bravo-Ureta et al. (2012), the biases stemming from unobserved variables were addressed using an SPF framework that corrects for such biases. Initial model diagnostics confirmed that selection bias was present; thus, providing justification for the combined framework.

The results of this study confirm the important role that several variables play on the adoption of certified seeds. In order to enhance technology adoption, there is a need to broaden the delivery of extension-related activities, including the provision of training, expansion of on-farm demonstrations and strengthening the support given by extension workers to farmers. In addition, improved access to credit will encourage the adoption of this technology. On the other hand, there is a need to offset factors that constrain the adoption of CSs including the improvement of drought management while giving support to farmers suffering from submergence.

Finally, analyses of the impact of adoption of CSs suggest that there are significant differences in performance between adopters and non-adopters. These differences are 
in terms of output and TE and in both cases adopters perform better. In other words, we uncover significant technological and managerial gaps both favouring adopters and these gaps are more pronounced after correcting for selection bias. Moreover, we find that the adoption of CSs can have a significant positive impact on the net income of rice farmers and thus on poverty alleviation.

\section{References}

Anderson, J. and Feder, G. 'Agricultural extension', in R. Evenson and P. Pingali (eds), Handbook of Agricultural Economics: Volume 3, Agricultural Development: Farmers, Farm Production and Farm Markets (Amsterdam: Elsevier, 2007 pp. 2343-2378).

Anon. 'Focus: Grain prices', The Economist, 1 May 2012. Available at: http://www.economist. com/blogs/graphicdetail/2012/05/focus (last accessed 24 September 2012).

Baker, K. and Jewitt, S. 'Evaluating 35 years of Green Revolution technology in villages of Bulandshahr district, western UP, North India', Journal of Development Studies, Vol. 43, (2007) pp. 312-339.

Balisacan, A. and Sebastian, L. 'Challenges and policy directions: Overview', in A. Balisacan and L. Sebastian and Associates (eds.), Securing Rice, Reducing Poverty: Challenges and Policy Directions (Los Baños: Southeast Asian Regional Center for Agriculture, 2006).

Balisacan, L., Sebastian, L. and Alpuerto, V.L.E (eds), Securing Rice, Reducing Poverty: Challenges and Policy Directions (Los Baños, Philippines: Southeast Asian Regional Center for Agriculture, 2006).

Battese, G. E. 'Frontier production functions and technical efficiency: A survey of empirical application in agricultural economics', Agricultural Economics, Vol. 7, (1992) pp. 185-208.

Battese, G. E. 'A note on the estimation of Cobb-Douglas production functions when some explanatory variables have zero values', Journal of Agricultural Economics, Vol. 48, (1997) pp. 250-252.

Becker, S. and Ichino, A. 'Estimation of average treatment effects based on propensity scores', Stata Journal, Vol. 2, (2002) pp. 358-377.

Beronio, R., Bordey, F., Eligio, A., Barroga, K., Malasa, R., Mariano, M. and Castaneda, A. 'Is the household income of rice farmers getting better over time?' Rice Science for Better Decision-Makers, Issue 1, (Muñoz, Philippines: Department of Agriculture - Philippine Rice Research Institute, 2010).

Bordey, F. H. and Nelson, C. H. 'Productivity of rice farming in the Philippines: Patterns and sources', Philippine Journal of Crop Science, Vol. 37, (2012) pp. 10-22.

Bravo-Ureta, B. E. and Pinheiro, A. E. 'Efficiency analysis of developing country agriculture: A review of the frontier function literature', Agricultural and Resource Economics Review, Vol. 22, (1993) pp. 88-101.

Bravo-Ureta, B. E., Solís, D., Moreira, V., Maripani, J., Thiam, A. and Rivas, T. 'Technical efficiency in farming: a meta-regression analysis', Journal of Productivity Analysis, Vol. 27, (2007) pp. 57-72.

Bravo-Ureta, B. E., Almeida, A., Solís, D. and Inestroza, A. 'The economic impact of Marena's investment on sustainable agricultural systems in Honduras', Journal of Agricultural Economics, Vol. 62, (2011) pp. 429-448.

Bravo-Ureta, B. E., Greene, W. and Solís, D. 'Technical efficiency analysis correcting for biases from observed and unobserved variables: An application to a natural resource management project', Empirical Economics, Vol. 43, (2012) pp. 55-72.

Caliendo, M. and Kopeinig, S. 'Some practical guidance on the implementation of propensity score matching', Journal of Economic Surveys, Vol. 22, (2008) pp. 31-72.

Cameron, A. and Trivedi, P. Microeconometrics: Methods and Applications (Cambridge: Cambridge University Press, 2005). 
Cavatassi, R., Gonzales-Flores, M., Winters, P., Andrade-Piedra, J., Espinosa, P. and Thiele, G. 'Linking smallholders to the new agricultural economy: The case of plataformas de concertacion in Ecuador', The Journal of Development Studies, Vol. 47, (2011) pp. 1545-1573.

Chirwa, E. 'Adoption of fertiliser and hybrid seeds by smallholder maize farmers in Southern Malawi', Development Southern Africa, Vol. 22, (2005) pp. 1-12.

Coelli, T., Estache, A., Perelman, S. and Trujillo, L. A primer on efficiency measurement for utilities and transport regulators. (Washington, DC: The World Bank, 2003).

Conning, J. and Udry, C. 'Rural financial markets in developing countries', in R. Evenson and P. Pingali (eds.), Handbook of Agricultural Economics: Volume 3, Agricultural Development: Farmers Farm Production and Farm Markets (Amsterdam: Elsevier, 2007, pp. 2857-2908).

Dawson, P. J. and Lingard, J. 'Measuring farm efficiency over time on Philippine rice farms', Journal of Agricultural Economics, Vol. 40, (1989) pp. 168-177.

Duwayri, M., Tran, D. V. and Nguyen, V. N. 'Reflections on yield gaps in rice production: How to narrow the gaps', in M. K. Papademetriou, F. J. Dent and E. M. Herath (eds), Bridging the Rice Yield Gap in the Asia Pacific Region (Bangkok: Food and Agriculture Organization of the United Nations - Regional Office for Asia and the Pacific, 2000 pp. 26-46).

Estudillo, J. and Otsuka, K. 'Lessons from three decades of Green Revolution in the Philippines', Developing Economies, Vol. 44, (2006) pp. 123-148.

Feder, G., Just, R. E. and Zilberman, D. 'Adoption of agricultural innovations in developing countries: A survey', Economic Development and Cultural Change, Vol. 33, (1985) pp. 255298.

Foster, A. and Rosenzweig, M. 'Microeconomics of technology adoption', Annual Review of Economics, Vol. 2, (2010) pp. 395-424.

Gonzales, L. A., Bordey, F. H., Sebastian, L. S., Redoña, E. D., Gonzales, A. A., Gonzales, V. A., Elca, C. D., Gonzales, A. A., Beltran, J. C., Casiwan, C. B., Mataia, A. B., Redondo, G. O., Arocena, A. A., Parayno, C. N. and Adriano, S. S. The Hybrid Rice Commercialization Program: Midterm Impact Assessment. Muñoz, Nueva Ecija: STRIVE Foundation and Philippine Rice Research Institute. 2007.

González-Flores, M., Bravo-Ureta, B., Solís, D. and Winters, P. 'The impact of high value markets on smallholder efficiency in the Ecuadorean Sierra: A stochastic production frontier approach correcting for selectivity bias', Food Policy, Vol. 44, (2014) pp. 237-247.

Greene, W. NLOGIT 4.0/LIMDEP Version 9.0 Reference Guide (Plainview, NY: Econometrics Software, Inc., 2007).

Greene, W. 'A stochastic frontier model with correction for sample selection', Journal of Productivity Analysis, Vol. 34, (2010) pp. 15-24.

Guo, S. and Fraser, M. W. Propensity Score Analysis: Statistical Methods and Applications (Thousand Oaks, CA: Sage Publications, 2010).

Heckman, J. 'Sample selection bias as a specification error', Econometrica, Vol. 47, (1979) pp. 153-161.

Huelgas, Z. and Templeton, D. 'Adoption of crop management technology and cost-efficiency impacts: The case of three reductions, three gains in the Mekong River Delta of Vietnam', in F. Palis, G. R. Singleton, M. Casimero and B. Hardy (eds.), Research to Impact: Case Studies for Natural Resource Management for Irrigated Rice in Asia (Los Baños, Philippines: International Rice Research Institute, 2010, pp. 289-315).

Imbens, G. and Wooldridge, J. Recent Developments in the Econometrics of Program Evaluation. Research Working Paper No. 14251 (Washington, DC: National Bureau of Economic Research, 2008).

IRRI 'Certified seed' (Manila: International Rice Research Institute, 2013). Available at: http:// www.knowledgebank.irri.org/postproductioncourse/factsheetsNRefences/Rice $\% 20 \% 20$ and $\% 20$ seed $\% 20$ quality $/$ Seed $\% 20$ Certification.doc (last accessed 18 July 2013).

Jara-Rojas, R., Bravo-Ureta, B. E. and Díaz, J. 'Adoption of water conservation practices: A socioeconomic analysis of small-scale farmers in Central Chile', Agricultural Systems, Vol. 110, (2012) pp. 54-62. 
Joshi, G. R. and Pandey, S. 'Farmers' perceptions and adoption of modern rice varieties in Nepal', Quarterly Journal of International Agriculture, Vol. 45, (2004) pp. 171-186.

Kalirajan, K. P. and Flinn, J. C. 'The measurement of farm-specific technical efficiency', Pakistan Journal of Applied Economics, Vol. 2, (1983) pp. 167-180.

Khandker, S. R., Koolwal, G. B. and Samad, H. A. Handbook on Impact Evaluation: Quantitative Methods and Practices (Washington, DC: World Bank, 2010).

Kshirsagar, K. G., Pandey, S. and Bellon, M. R. 'Farmer perceptions, varietal characteristics and technology adoption: A rainfed rice village in Orissa', Economic and Political Weekly, Vol. 37, (2002) pp. 1239-1246.

Kumbhakar, S., Tsionas, M. and Sipilainen, T. 'Joint estimation of technology choice and technical efficiency: An application to organic and conventional dairy farming, Journal of Productivity Analysis, Vol. 31, (2009) pp. 151-162.

Laborte, A., de Bie, C. A. J. M., Moya, P., Boling, A. A. and van Ittersum, M. K. 'Rice yields and yield gaps in Southeast Asia: Past trends and future outlook', European Journal of Agronomy, Vol. 36, (2012) pp. 9-20.

Lai, H., Polachek, S. and Wang, H. Estimation of Stochastic Frontier Model with a Sample Selection Problem, Working Paper (Chia-Yi, Taiwan: Department of Economics, National Chung Cheng University, 2009).

Leuven, E. and Sianesi, B. PSMATCH2: STATA module to perform full Mahalanobis and propensity score matching, common support graphing, and covariate imbalance testing, Statistical Software Components Series S432001 (Chestnut Hill, MA: Department of Economics, Boston College, 2003).

Lobell, D., Cassman, K. and Field, C. 'Crop yield gaps: Their importance, magnitudes and causes', Annual Review of Environment and Resources, Vol. 34, (2009) pp. 179-204.

Makarim, A. K. 'Bridging the yield gap in Indonesia', in M. K. Papademetriou, F. J. Dent and E. M. Herath (eds.), Bridging the Rice Yield Gap in the Asia Pacific Region (Bangkok: Food and Agriculture Organization of the United Nations Regional Office for Asia and the Pacific, 2000, pp. 112-121).

Malasa, R. B. and Velayo, M. C. Adoption of High Quality Seeds and 40 Kilogram Seeding Rate/Hectare. IFHAP derivative paper (Manila: Philippine Rice Research Institute, 2009).

Manalili, R. G., Malasa, R. B., Casiwan, C. B., Balatazar, M. M., Parayno, C. N., Nievera, M. R. and Bordey, F. H. What is the Status of Hybrid Rice Adoption in the Philippines?. IFHAP derivative paper (Manila: Philippine Rice Research Institute, 2008).

Mariano, M., Villano, R. and Fleming, E. 'Are irrigated farming ecosystems more productive than rainfed farming systems in rice production in the Philippines?', Agriculture, Ecosystems and Environment, Vol. 139, (2010) pp. 603-610.

Mariano, M., Villano, R. and Fleming, E. 'Technical efficiency of rice farms in different agroclimatic zones in the Philippines: An application of a stochastic metafrontier model', Asian Economic Journal, Vol. 25, (2011) pp. 245-269.

Mariano, M., Villano, R. and Fleming, E. 'Factors influencing farmers' adoption of modern rice technologies and good management practices in the Philippines', Agricultural Systems, Vol. 110, (2012) pp. 41-53.

Mataia, A., Jamora, N., Moya, P., Francisco, S. and Dawe, D. 'Sources of decade rice yield growth in the Philippines', Philippine Journal of Crop Science, Vol. 36, (2011) pp. 20-29.

Mayen, C., Balagtas, J. and Alexander, C. 'Technology adoption and technical efficiency: Organic and conventional dairy farms in the United States', American Journal of Agricultural Economics, Vol. 92, (2010) pp. 181-195.

Mueller, N. D., Gerber, J. S., Johnston, M., Ray, D. K., Ramankurty, N. and Foley, J. 'Closing the yield gaps through nutrient and water management', Nature, Vol. 490.7419, (2012) pp. 254-257.

Neuman, K., Verburg, P. H., Stehfest, E. and Muller, C. 'The yield gap of global grain production: A spatial analysis', Agricultural Systems, Vol. 103, (2010) pp. 316-326. 
Nin-Pratt, A., Johnson, M., Magalhaes, E., You, L., Diao, X. and Chamberlain, J. Yield Gaps and Potential Agricultural Growth in West and Central Africa, Research Monograph (Washington, DC: International Food Policy Research Institute, 2011).

O'Donnell, C. J., Rao, D. S. P. and Battese, G. E. 'Metafrontier frameworks for the study of firm-level efficiencies and technology ratios', Empirical Economics, Vol. 34, (2008) pp. 231255.

Pate, N. T. and Cruz, A. T. Technical Efficiency of Philippine Rice-producing Region: An Econometric Approach, Paper presented at the 10th National Convention on Statistics, Manila (2007).

Pufahl, A. and Weiss, C. 'Evaluating farm programmes: Results from propensity score matching', European Review of Agricultural Economics, Vol. 36, (2009) pp. 79-101.

Rahman, S., Wiboonpongse, A., Sriboonchitta, S. and Chaovanapoonphol, Y. 'Production efficiency of Jasmine rice producers in northern and north-eastern Thailand', Journal of Agricultural Economics, Vol. 60, (2009) pp. 419-435.

Rejesus, R., Palis, F., Rodriquez, D. and Lampayan, R. "Impact of alternate wetting and drying (AWD) water-saving irrigation technique: Evidence from rice producers in the Philippines', Food Policy, Vol. 36, (2011) pp. 280-288.

Revilla-Molina, I., Bastiaans, L., van Keulen, H., Mew, T. W., Zhu, Y. Y. and Villano, R. A. 'Improvement of technical efficiency in rice farming through interplanting: A stochastic frontier analysis in Yunnan China', in I. Revilla-Molina (ed.), Genetic Diversity for Sustainable Rice Management in China: Adoption and Impact (Wageningen, The Netherlands: Wageningen University, 2009, pp. 57-66.).

Rola, A. and Quintana-Alejandrino, J. T. 'Technical efficiency of Philippine rice farmers in irrigated, rainfed lowland and upland environments: A frontier production function analysis', Philippine Journal of Crop Science, Vol. 18, (1993) pp. 56-69.

Saito, K., Sokei, Y. and Wopereis, M. C. S. 'Enhancing rice productivity in West Africa through genetic improvement', Crop Science, Vol. 52, (2012) pp. 484-493.

Salehin, M. M., Kabir, M. S., Morshed, K. M. and Farid, K. S. 'Socioeconomic changes of farmers due to adoption of rice production technologies in selected areas of Sherpur district', Journal of the Bangladesh Agricultural University, Vol. 7, (2009) pp. 335-341.

Sebastian, L., Alviola, P. A. and Francisco, S. R. 'Bridging the rice yield gap in the Philippines', in M. K. Papademetriou, F. J. Dent and E. M. Herath (eds.), Bridging the Rice Yield Gap in the Asia-Pacific Region (Bangkok: Food and Agriculture Organization of the United Nations Regional Office for Asia and the Pacific, 2000, pp. 122-134).

Singha, A. K. and Baruah, M. J. 'Farmers' adoption behaviour in rice technology: An analysis of adoption behaviour of farmers in rice technology under different farming systems in Assam', Journal of Human Ecology, Vol. 35, (2011) pp. 167-172.

Sipilainen, T. and Oude Lansink, A. Learning in Switching to Organic Farming. NJF-Seminar 369, NJF Report Volume 1 No. 1 (Tartu, Estonia: Nordic Association of Agricultural Scientists, 2005).

Smith, J. and Todd, P. 'Does matching overcome LaLonde's critique of non-experimental estimators?', Journal of Econometrics, Vol. 125, (2005) pp. 305-353.

Solís, D., Bravo-Ureta, B. E. and Quiroga, R. 'Soil conservation and technical efficiency among hillside farmers in Central America: A switching regression model', Australian Journal of Agricultural and Resource Economics, Vol. 51, (2007) pp. 491-510.

Tenywa, M. M., Rao, K. P. C., Tukahirwa, J. B., Buruchara, R., Adekunle, A. A., Mugabe, J., Wanjiku, C., Mutabazi, S., Fungo, B., Kashaija, N. I., Pali, P., Mapatano, S., Ngaboyisonga, C., Farrow, A., Njuki, J. and Abenakyo, A. 'Agricultural innovation platform as a tool for development oriented research: Lessons and challenges in the formation and operationalization', Learning Publics Journal of Agriculture and Environmental Studies, Vol. 2, (2011) pp. $117-146$. 
Tiamiyu, S. A., Akintola, J. O. and Rahji, M. A. Y. 'Technology adoption and productivity difference among growers of new rice for Africa in Savanna Zone of Nigeria', Tropicultura, Vol. 27, (2009) pp. 193-197.

Tiongco, M. and Dawe, D. 'Long-term evolution of productivity in a sample of Philippine rice farms: Implications for sustainability and future research', World Development, Vol. 30, (2002) pp. 891-898.

Umetsu, C., Lekprichakul, T. and Chakravorty, U. 'Efficiency and technical change in the Philippines rice sector: A Malmquist total factor productivity analysis', American Journal of Agricultural Economics, Vol. 85, (2003) pp. 943-963.

Villano, R. and Fleming, E. 'Technical efficiency and production risk in rice farming: Evidence from Central Luzon Philippines', Asian Economic Journal, Vol. 20, (2006) pp. 29-46.

Winters, P., Salazar, L. and Maffioli, A. Designing Impact Evaluations for Agricultural Projects (Washington, DC: Strategy Development Division, Inter-American Development Bank, 2010). Available online at: http://idbdocs.iadb.org/wsdocs/getdocument.aspx?doc num $=35529432$ (last accessed 12 August 2013).

Wu, H., Ding, S., Pandey, S. T. and Tao, D. 'Assessing the impact of agricultural technology adoption on farmers' well-being using propensity score matching analysis in rural China', Asian Economic Journal, Vol. 24, (2010) pp. 141-160.

Yao, R. and Shively, G. E. 'Technical change and productive efficiency: Irrigated rice in the Philippines', Asian Economic Journal, Vol. 21, (2007) pp. 155-168. 